\section{Welcome from the Co-Editors}

\author{
Dear JSESD Readers and Supporters,
}

We are very pleased to present the inaugural issue of Journal of Science Education for Students with Disabilities (JSESD) in an online and open source format (no worries, it can still be obtained in print). This issue also represents the first issue for which we are co-editors.

We have been diligent about ensuring that the journal is published with attention to maximizing access, potential growth, and integrity since taking over the editorial responsibilities. Some of the notable changes to this Winter, 2007 [12(1)] issue include:

1. In addition to the traditional print version, the journal is also available in an online version. The online version will reside free-of-charge on Rochester Institute of Technology's (RIT) Wallace Library server, and can be found at http://library.rit.edu/oajournals/index.php/jsesd. For a minimal fee, the journal can be professionally printed, bound, and shipped by clicking on the lulu.com link at the above web address.

2. We have been assigned an ISSN by the Library of Congress for the online version of the journal to go along with the print version.

3. Due to reasons of cost, wide-spread dissemination, and publishing logistics, the journal is being published as "Open Access". If you are unfamiliar with "Open Access" publishing, please see the piece written by Peter Suber at the following link: http://www.earlham.edu/ peters/fos/brief.htm.

4. We recruited the talented RIT/NTID Arts \& Imaging Studies Professor, Cathy Chou, to create the aesthetic journal cover. The background DNA image was strategically chosen to symbolize the interplay of JSESD's readership; that of experts in various fields of disabilities along with experts in the disciplines of science. The two intertwined sides of the double helix backbone represent this relationship. The rungs of the DNA structure represent the various age groups (K-Postsecondary) of students upon which this journal focuses.

5. In future editions, we plan to expand the journal to include interesting and relevant sections including:

- Editorials

- Research Articles

- Teaching Techniques

- Product Reviews

- Cyber Links

We actively encourage people to submit articles that fit any of the above sections (see the "Author Guidelines" section of the journal for manuscript preparation instruction).

$J S E S D$ remains a quality peer-reviewed journal. We are very excited about the new direction of the journal and some of the inherent growth potential that comes with joining the "Open Access" publication movement.

Sincerely,

\section{L.K. Quinsland \& Todd Pagano}

\author{
L.K. Quinsland and Todd Pagano \\ Co-Editors, Journal of Science Education \\ for Students with Disabilities \\ Professors, Rochester Institute of \\ Technology/ \\ National Technical Institute for the Deaf
}

